\title{
From blue skies science to practical application: Increasing need for retrospectivein environmental micropaleontological monitoring (REMM)
}

\author{
Elisabeth Alve \\ Department of Geosciences, University of Oslo, Norway \\ ealve@geo.uio.no
}

The European Water Framework Directive (WFD) focuses on the protection of groundwater, inland surface waters, estuarine waters, and coastal waters. One of the central themes in the implementation Guidance document concerning "Transitional and Coastal Waters" is defining biological reference conditions. This is in contrast to governmental bodies' traditional sole focus on contemporary environmental monitoring and opens new possibilities for environmental micropaleontology.

Improved knowledge of benthic foraminiferal ecology, combined with dating and geochemical methods to trace changes in environmental parameters back in time, has strengthened our ability to perform paleoecological interpretations integrated with a time-scale. As a result of this, we see a growing body of retrospective studies from all over the world, linking faunal changes over the past few centuries to natural and/or anthropogenic causes. Yet, our main audience for these papers is our scientific colleagues. However, the European initiative appreciates that information about "background conditions" and natural variability is crucial when planning improvement strategies; this represents a major opportunity for micropaleontologists to get retrospective studies incorporated into governmental guidelines for environmental investigation. This will create new employment opportunities for our students. A major challenge now is to make our governmental authorities aware of the unique potential micropaleontology has to approach some of the problems they are facing. Retrospective Environmental Micropaleontological Monitoring (REMM):

1) can provide biological reference conditions for any given soft bottom area with net sediment accumulation (> about $1 \mathrm{~mm} / \mathrm{yr}$ ) several hundred years back in time;

2) can provide data on natural variability as well as high resolution timeseries of environmental change in estuarine and coastal sediment accumulation areas; 
3) is extremely cost efficient as compared to traditional biological monitoring;

4) is gentle on the environment - only involves physical disturbance of a fraction of the soft bottom habitat as compared to traditional biological sampling.

In order to make our methods attractive and applicable, we need to specify strengths and limitations, establish good ecological calibration sets, and to improve our quantitative approaches. Marty Buzas has educated us on the latter and it is now up to us to take it a step further. Improved knowledge of quantitative relationships between faunal and environmental parameters is particularly needed. The Norwegian Pollution Control Authority's classification system for environmental quality includes a classification for soft-bottom macrofauna. It is currently being modified and incorporated into the implementation strategy for WFD. Recently, this system has been applied to modern benthic foraminiferal assemblages as well as to fossil ones in dated sediment cores from sill basins along the southern Norwegian coast. Distributional data show a significant correlation between several faunal parameters and annual dissolved oxygen minimum concentrations (bottom water). Application of the governmental classification system for environmental quality shows the same pattern whether used on soft-bottom macrofauna or on benthic foraminifera. These ecological training sets have allowed reconstruction of the successive environmental change (transition from one environmental class to another) within areas of different present-day environmental status. These results are very promising and illustrate the significance of REMM. 